\title{
Особенности государственного управления в области киберспорта
}

\author{
Редькина А.И. \\ Московский государственный юридический университет имени О.Е. Кутафина (МГЮА), \\ 125993, Россия, Москва, Садовая-Кудринская ул., 9 \\ E-mail: juriste.ap@gmail.com
}

\begin{abstract}
Аннотация. Компьютерный спорт (киберспорт) в настоящее время динамично развивается, развиваются и подходы к правовому обеспечению в данной сфере с учетом как специфики самого спорта в целом, так и особенностей данного направления. В силу того, что киберспорт является сравнительно молодым направлением, в настоящее время отсутствуют универсальные подходы к правовому регулированию и государственному управлению в данной области на национальном уровне. Особенности правового обеспечения и государственного управления в сфере киберспорта, хотя и являются предметом научного интереса как российских, так и зарубежных ученых, не исследованы в полной мере. В связи с этим автором рассмотрены некоторые специфические особенности киберспорта как предметно-объектной области государственного управления с учетом представленных в научной литературе позиций, приведены существующие подходы к реализации государственного управления в данной сфере на примере Франции, США, Республики Корея. В результате выделены наиболее применимые модели государственного управления в области киберспорта. Сделан вывод о том, что наиболее целесообразным будет не включение в законодательство о спорте новых специализированных положений, касающихся лишь киберспорта, а совершенствование общего правового регулирования в этой области, в том числе в части защиты интеллектуальных прав.
\end{abstract}

Ключевые слова: спорт, спортивное право, административное право, государственное управление, компьютерный спорт, киберспорт.

Для цитирования: Редькина А.И. 2020. Особенности государственного управления в области киберспорта. NOMOTHETIKA: Философия. Социология. Право. 45 (3): 550-557. DOI 10.18413/2712746X-2020-44-3-550-557

\section{Features of public administration in the field of esports}

\author{
Alena I. Redkina \\ Kutafin Moscow State Law University (MSAL), \\ 9 Sadovaya-Kudrinskaya St, Moscow, 123995, Russia \\ E-mail: juriste.ap@gmail.com
}

\begin{abstract}
Esports is currently developing dynamically, and approaches to legal regulation in this area are also developing, taking into account both the specifics of the sport itself in general and the characteristics of eSports. Due to the fact that eSports is a relatively young area, there are currently no universal approaches to legal regulation and public administration in this sphere at national level. In addition, the peculiarities of legal regulation and public administration in the field of e-sports have not been fully researched in the scientific literature. In this regard, the author examines some of the specific features of eSports as a subject-object area of public administration, taking into account the positions presented in the scientific literature, presents the existing approaches to the implementation of public administration in this area on the example of France, the USA, and the Republic of Korea. As a result, the most applicable models of public administration in the field of eSports have been identified. It was concluded that it would be most appropriate not to include new specialized provisions concerning only eSports in the
\end{abstract}


sports legislation, but to improve the general legal regulation in this area, including the protection of intellectual rights.

Keywords: sports, sports law, administrative law, public administration, computer sports, eSports.

For citation: Redkina A.I. 2020. Features of public administration in the field of esports. NOMOTHETIKA: Philosophy. Sociology. Law series. 45 (3): 550-557 (in Russian). DOI 10.18413/2712-746X-2020-44-3-550-557

\section{Введение}

В 2020 году глобальная экономика киберспорта может принести доходы в размере 1,1 миллиарда долларов, при этом большая их часть $(74,8$ \%) будет получена от спонсорства и реализации интеллектуальных прав, включая права на освещение мероприятий. Мировая аудитория киберспорта достигнет 495 миллионов человек. По мере развития рынка киберспорта будут внедряться и совершенствоваться новые способы получения доходов от проведения соревнований по компьютерному спорту [NewZoo, 2020].

Компьютерный спорт (далее - киберспорт) был включен во Всероссийский реестр видов спорта в 2016 году (Приказом Министерства спорта РФ от 29 апреля 2016 г. № 470 «О признании и включении во Всероссийский реестр видов спорта спортивных дисциплин, видов спорта и внесении изменений во Всероссийский реестр видов спорта, а также в приказ Министерства спорта, туризма и молодежной политики Российской Федерации от 17.06.2010 № 606 "О признании и включении видов спорта, спортивных дисциплин во Всероссийский реестр видов спорта"»).

В соответствии с Правилами вида спорта «компьютерный спорт», утвержденными приказом Министерства спорта Российской Федерации от 22 января 2020 г. № 22, под компьютерным спортом понимается вид соревновательной деятельности и специальной практики подготовки к соревнованиям на основе компьютерных и (или) видеоигр, где игра предоставляет среду взаимодействия объектов управления, обеспечивая равные условия состязаний человека с человеком или команды с командой.

В силу того, что правовое регулирование деятельности, реализуемой в области киберспорта, находится в настоящее время на этапе развития, дальнейшее формирование подходов к правовому обеспечению и публичному управлению в этой области требует надлежащего научного осмысления. Среди исследователей, поднимавших в своих работах проблемы правового регулирования киберспорта в различных его аспектах, можно отметить Е.В. Воскресенскую, А.Н. Лойко [2019], М.В. Демченко, А.Д Шведову [2019], Е.В. Сутырину [2018], Д.Б. Чакар, М. Йигит [Çakar, Yiğit, 2019], Й. Харттунг [Harttung, 2015], Дж. Холден, Р. Роденберг, А. Кабуракис [Holden, Rodenberg, Kaburakis, 2017], К. Холлист [Hollist, 2015], Дж. Мартинелли [Martinelli, 2019], M. Оуэнс [Owens, 2016], С. Вансингель, Э. Велпри, Н. Бесомбс [Vansyngel, Velpry, Besombes, 2018], Э. Уиндхольц [Windholz, 2020], Янг Юэ [Yue, 2018].

Специфика киберспорта, в том числе как вида спорта, а также его существенный экономический потенциал требуют реализации эффективных и выверенных подходов к государственному управлению в данной области.

Настоящая статья посвящена исследованию особенностей государственного управления в области компьютерного спорта.

\section{Специфика киберспорта как предметно-объектной области государственного управления}

Компьютерный спорт в настоящее время является признанным видом спорта не во всех странах, поэтому актуальны еще дискуссии относительно возможности и целесооб- 
разности распространения на деятельность в данной сфере общих положений профильного спортивного законодательства. Специфика компьютерного спорта затрудняет применимость к нему в полной мере отдельных институтов спортивного права.

В качестве одного из специфических аспектов киберспорта Йохен Харттунг выделяет вовлеченность в него множества сторон, которые имеют соответствующие экономические интересы, не всегда совместимые [Harttung, 2015]. В частности, на передний план выходят производители видеоигр главным образом с позиции защиты своих интеллектуальных прав, реализация которых является основным источником дохода в индустрии компьютерного спорта. При этом существующая система не всегда дает четкий ответ на вопрос о том, кому именно принадлежат соответствующие права на мероприятие - организатору мероприятия или издателю игры [Martinelli, 2019]. Фактическими руководящими органами проводимых киберспортивных соревнований являются издатели игр [Windholz, 2020].

Одной из особенностей киберспорта является также отсутствие обязательной привязки к конкретному месту проведения соревнований, которая может быть характерна для иных видов спорта [Windholz, 2020]. Кроме того, индустрия киберспорта динамично развивается, со временем некоторые игры теряют популярность, и это происходит быстрее, чем с иными видами спорта [Holden, Rodenberg, Kaburakis, 2017].

Другая особенность киберспорта заключается в его существенной коммерческой ориентированности. Несмотря на то, что многие другие виды спорта в настоящее время в значительной степени подверглись коммерциализации, и организация и проведение соревнований по ним приносят высокие доходы, они не создавались с целью маркетинга и увеличения продаж конкретной продукции, в отличие от киберспорта [Windholz, 2020]. Но хотя индустрия киберспорта «выросла» из видеоигр, в настоящее время она идет по пути развития состязательного и профессионального спорта [Yue, 2018]. К тому же проведение соревнований по киберспорту генерирует существенные возможности для получения доходов от рекламы [Hollist, 2015].

Джон Холден, Райан Роденберг и Анастасиос Кабуракис отмечают измененный формат трансляции киберспортивных мероприятий, отличный от формата освещения мероприятий по иным видам спорта [Holden, Rodenberg, Kaburakis, 2017].

Говоря о взаимодействии компьютерного спорта и иных видов спорта, обладающих более длительной историей существования, исследователи отмечают, что, хотя компьютерный спорт и основан на применении инновационных технологий, он не оказывает, в отличие от применения инноваций в некоторых иных областях, вытесняющего воздействия на другие виды спорта, напротив, предлагет новые возможности для них, привлекая новую аудиторию и предоставляя новые источники доходов [Windholz, 2020].

Организация и проведение мероприятий по компьютерному спорту актуализирует вопрос защиты персональных данных спортсменов. Актуальными для развития государственного управления в области киберспорта являются и вопросы противодействия применению допинга. Поскольку в России киберспорт признан видом спорта, на него распространяются соответствующие антидопинговые нормы.

Говоря о целостности компьютерного спорта, исследователи отмечают необходимость реализации специального международного сотрудничества в данной области с учетом мобильности рынков азартных игр [Holden, Rodenberg, Kaburakis, 2017].

\section{Некоторые подходы к реализации государственного управления в области киберспорта}

В силу того, что киберспорт является сравнительно молодым направлением и динамично развивается, в настоящее время отсутствуют широко распространенные универсальные подходы к правовому регулированию и государственному управлению в данной области на национальном уровне. 
Можно выделить следующие виды подходов к правовому обеспечению киберспорта:

- отсутствие признания киберспорта в качестве самостоятельного вида спорта, при этом на соответствующую деятельность распространяется общий правовой режим, без учета специфики ее чисто спортивной составляющей (в качестве примера можно привести Францию);

- признание киберспорта в качестве отдельного вида спорта, в силу чего к соответствующей деятельности применяются общие принципы спортивного законодательства без учета его специфики (Россия);

- наличие специализированного правового регулирования в области киберспорта (в качестве примера можно привести опыт Республики Корея).

Рассмотрим далее эти подходы на некоторых примерах.

В Республике Корея сравнительно недавно действует специализированный нормативно-правовой акт в области компьютерного спорта. В соответствии со статьей 1 Закона Республики Корея от 2012 года (в редакции от 2016 года) «О продвижении киберспорта», целью данного акта является создание инфраструктуры для культуры и индустрии киберспорта, обеспечение расширения возможностей населения для участия в киберспорте в досуговых целях, а также обеспечение устойчивого развития национальной экономики в данной области.

В данном законе закрепляются понятия киберспорта, профессионального киберспорта, массового киберспорта («киберспорта для всех»), киберспортивной индустрии, киберспортивных сооружений, игроков в киберспорт, а также понятие киберспортивной организации (статья 2 Закона Республики Корея от 2012 года (в редакции от 2016 года) «О продвижении киберспорта»). При этом соответствующие определения являются достаточно формальными и практически не отражают сущностных характеристик указанных категорий.

Закон Республики Корея от 2012 года (в редакции от 2016 года) «О продвижении киберспорта» направлен главным образом на создание правовой основы для взаимодействия между органами публичной власти различных уровней в целях обеспечения развития киберспорта, причем как профессионального, так и массового.

Статья 4 Закона Республики Корея от 2012 года (в редакции от 2016 года) «О продвижении киберспорта» устанавливает обязанность национальных и местных органов публичной власти разрабатывать и реализовывать политику, направленную на продвижение киберспорта.

Для целей развития массового киберспорта предусматривается возможность местных органов публичной власти обеспечивать создание необходимой инфраструктуры и проводить мероприятия по компьютерному спорту (статья 5 Закона Республики Корея от 2012 года (в редакции от 2016 года) «О продвижении киберспорта»).

Для достижения целей данного нормативно-правового акта на национальном уровне разрабатываются документы стратегического планирования на различные периоды, в рамках которых могут затрагиваться, в частности, следующие вопросы:

- основные направления продвижения киберспорта;

- создание инфраструктуры для активизации киберспорта;

- подготовка профессиональных кадровых ресурсов для киберспорта и обеспечение защиты их прав и интересов;

- продвижение международных мероприятий по компьютерному спорту;

- обеспечение финансирования продвижения киберспорта;

- содействие научной деятельности в области киберспорта и создание необходимой инфраструктуры (согласно статье 6 Закона Республики Корея от 2012 года (в редакции от 2016 года) «О продвижении киберспорта»). 
Кроме того, в целях разработки и реализации государственной политики в области киберспорта органы публичной власти отслеживают фактическое состояние отрасли киберспорта (статья 7 Закона Республики Корея от 2012 года (в редакции от 2016 года) «О продвижении киберспорта»).

В соответствии со статьей 8 Закона Республики Корея от 2012 года (в редакции от 2016 года) «О продвижении киберспорта» национальные и местные органы публичной власти могут осуществлять финансирование киберспорта за счет средств бюджетов, в частности, в целях повышения конкурентоспособности национального киберспорта или строительства соответствующей инфраструктуры.

Данный нормативно-правовой акт также закрепляет основы взаимодействия органов публичной власти с организациями частного сектора в данной сфере.

Во Франции компьютерный спорт не подпадает под действие Спортивного кодекса Франции, однако некоторые специализированные положения содержатся в Кодексе внутренней безопасности Франции, в структуру законодательной и регламентарной частей которого были включены соответствующие главы.

B соответствии со статьей L321-8 Кодекса внутренней безопасности Франции в соревновании по видеоиграм состязаются по меньшей мере два игрока или команды за счет или победу. Статья L321-9 устанавливает условия, касающиеся финансовых аспектов организации таких соревнований (в частности, предусматривается, что размеры денежных сборов, взимаемых с участников, не должны превышать определенного предела, устанавливаемого Государственным советом) в целях превенции организации незаконных азартных игр. Организатор такого мероприятия обязан предварительно сообщать о его проведении органам публичной власти.

Также статьей L321-10 Кодекса внутренней безопасности Франции отдельно регламентируется участие несовершеннолетних в киберспортивных мероприятиях.

Среди государств, законодательства которых содержат нормы, касающиеся непосредственно компьютерного спорта, можно выделить также США (на примере штата Мэриленд). Положения, касающиеся организации соревнований по киберспорту, содержатся в Уголовном кодексе штата Мэриленд, в статье 12-114. Согласно данной статье под киберспортивным соревнованием понимается соревнование с использованием видеоигр, в том числе шутеров от первого лица, стратегий в реальном времени и многопользовательских боевых онлайн-арен, в котором игроки соревнуются друг с другом и ключевым элементом, определяющим результаты, является относительное мастерство игроков. Организатор мероприятия вправе устанавливать призы, в том числе денежные, для победителей такого соревнования.

По мнению Эрика Уиндхольца, подход к публичному управлению в области киберспорта должен в определенной мере отличаться от подхода, реализуемого в отношении иных видов спорта, в силу специфических характеристик общественных отношений в области киберспорта как объекта государственного управления [Windholz, 2020].

Янг Юэ указывает на необходимость реализации подхода, учитывающего высокую степень профессионализации киберспорта, который позволит решить проблемы, касающиеся социальной защиты спортсменов, которые вынуждены заканчивать свою карьеру сравнительно рано [Yue, 2018].

Как указывают Джон Холден, Райан Роденберг и Анастасиос Кабуракис, регулирование сферы киберспорта требует реализации комплексного подхода [Holden, Rodenberg, Kaburakis, 2017], обусловленного тем, что затрагиваются в равной мере такие области, как спорт (в частности, с учетом его автономности), предпринимательская деятельность и технологические инновации [Windholz, 2020]. 
Компьютерный спорт в гораздо большей степени (по сравнению с иными видами спорта) отражает влияние процессов глобализации на спортивную деятельность, что также может сказываться на специфике государственного управления в этой области.

\section{Заключение}

В заключение отметим, что развитие законодательства в сфере спорта и совершенствование подходов к государственному управлению в этой области в целом должно осуществляться с учетом новых вызовов, в том числе обусловленных развитием технологий. Поэтому, возможно, наиболее целесообразным в контексте надлежащего правового обеспечения компьютерного спорта будет не включение в законодательство о спорте новых специализированных положений, касающихся лишь данного вида спорта, а совершенствование общего правового регулирования в этой области, в том числе в части защиты интеллектуальных прав в сфере спорта.

\section{Список источников}

1. Закон Республики Корея от 2012 года (в редакции от 2016 года) «О продвижении киберспорта» [이스포츠(전자스포츠) 진흥에 관한 법률]. Available at: http://www. law.go.kr/\%EB\%B2\%95\%EB\%A0\%B9/\%EC\%9D\%B4\%EC\%8A\%A4\%ED\%8F\%AC\%EC\%B 8\%А0\%28\%ЕC\%А0\%84\%ЕС\%9E\%90\%ЕС\%8А\%A4\%ED\%8F\%АC\%ЕС\%В8\%A0\%29\%ЕС \%A7\%84\%ED\%9D\%A5\%EC\%97\%90\%ЕA\%B4\%80\%ED\%95\%9C\%ЕB\%B2\%95\%ЕВ\%А5\% A0/(13971) (accessed 28 July 2020).

2. Кодекс внутренней безопасности Франции [Code de la sécurité intérieure (France)]. Available at: https://www.legifrance.gouv.fr/affichCode.do;jsessionid=21B34A09CD738A 14976277195E4C9BE5.tplgfr34s_2?cidTexte=LEGITEXT000025503132\&dateTexte=2020072 9 (accessed 28 July 2020).

3. Спортивный кодекс Франции [Code du sport (France)]. Available at: https://www.legifrance.gouv.fr/affichCode.do;jsessionid=D31EB86DFFC5598ED9A5B4532405 7492.tplgfr34s_2?cidTexte=LEGITEXT000006071318\&dateTexte=20200729 (accessed 28 July 2020).

4. Уголовный кодекс штата Мэриленд [Maryland Criminal Law (Annotated Code of Maryland)]. Available at: https://advance.lexis.com/ (accessed 28 July 2020).

\section{Список литературы}

1. Воскресенская Е.В., Лойко А.Н. 2019. Правовое регулирование киберспорта (компьютерного спорта) в Российской Федерации. Colloquium- journal, 13 (37): 176- 178.

2. Демченко М.В., Шведова А.Д. 2019. Правовое регулирование киберспорта в России и за рубежом. Инноватика и экспертиза: научные труды, 2 (27): 88- 93.

3. Сутырина Е.В. 2018. Правовое регулирование деятельности киберспортивной организации (клуба). Universum: экономика и юриспруденция, 1 (46): 10-13.

4. Çakar D.B., Yiğit M.H. 2019. eSports eSports Regulations and Problematics. The Journal of Eurasia Sport Sciences \& Medicine, 1 (3): 123-137.

5. Harttung J. 2015. The issue of «deep control» in professional esports - a critical analysis of intellectual property structures in electronic gaming. A thesis submitted in conformity with the requirements for the degree of Master of Laws. Toronto, 60. Available at: https://pdfs.semanticscholar.org/9622/3d754a68bac15cd6055fdc3e37c1c8ac3bcf.pdf (accessed 28 July 2020).

6. Holden J.T., Rodenberg R.M., Kaburakis A. 2017. Esports Corruption: Gambling, Doping, and Global Governance. Maryland Journal of International Law, 32: 236-273. Available 
at: https://digitalcommons.law.umaryland.edu/cgi/viewcontent.cgi?article=1663\&context=mjil (accessed 28 July 2020).

7. Hollist K.E. 2015. Time to be grown- ups about video gaming: the rising esports industry and the need for regulation. Arizona Law Review, 57: 823-847. Available at: https://arizonalawreview.org/pdf/57-3/57arizlrev823.pdf (accessed 28 July 2020).

8. Martinelli J. 2019. The Challenges of Implementing a Governing Body for Regulating ESports. University of Miami International and Comparative Law Review, 26 (2): 499-424. Available at: https://repository.law.miami.edu/cgi/viewcontent.cgi?article=1329\&context=umiclr (accessed 28 July 2020).

9. NewZoo. 2020. 2020 Global Esports Market Report. Available at: https://strivesponsorship.com/wp-content/uploads/2020/03/Global-Esports-Market-Report2020.pdf (accessed 28 July 2020).

10. Owens M.D. 2016. What's in a Name? eSports, Betting, and Gaming Law. Gaming law review and economics, 20 (7): 567- 570.

11. Vansyngel S., Velpry A., Besombes N. 2018. French esports institutionalization. In: Proceedings of the 2nd International GamiFIN Conference (Pori, Finland, May 21-23, 2018). Pori: $123-130$.

12. Windholz E.L. 2020. Governing Esports: Public Policy, Regulation and the Law (2020). Sports Law eJournal, 1 (1): 1-37.

13. Yue Y. 2018. Research on eSports and eSports Industry in China. Available at: https://library.olympic.org/Default/doc/SYRACUSE/174917/research-on-esports-and-esportsindustry-in-china-yang-yue?_lg=en-GB (accessed 28 July 2020).

\section{References}

1. Voskresenskaya E.V., Lojko A.N. 2019. Pravovoe regulirovanie kibersporta (komp'yuternogo sporta) v Rossijskoj Federacii [Legal regulation of cybersport (computer sports) in the Russian Federation.]. Colloquium-journal, 13 (37): 176-178.

2. Demchenko M.V., SHvedova A.D. 2019. Pravovoe regulirovanie kibersporta v Rossii i za rubezhom [Legal regulation of esports in Russia and abroad]. Innovatika i ekspertiza: nauchnye trudy, 2 (27): 88-93.

3. Sutyrina E.V. 2018. Pravovoe regulirovanie deyatelnosti kibersportivnoj organizacii (kluba) [Legal regulation of the activities of an eSports organization (club)]. Universum: ekonomika i yurisprudenciya, 1 (46): 10-13.

4. Çakar D.B., Yiğit M.H. 2019. eSports eSports Regulations and Problematics. The Journal of Eurasia Sport Sciences \& Medicine, 1 (3): 123-137.

5. Harttung J. 2015. The issue of «deep control» in professional esports - a critical analysis of intellectual property structures in electronic gaming. A thesis submitted in conformity with the requirements for the degree of Master of Laws. Toronto, 60. Available at: https://pdfs.semanticscholar.org/9622/3d754a68bac15cd6055fdc3e37c1c8ac3bcf.pdf (accessed 28 July 2020).

6. Holden J.T., Rodenberg R.M., Kaburakis A. 2017. Esports Corruption: Gambling, Doping, and Global Governance. Maryland Journal of International Law, 32: 236-273. Available at: https://digitalcommons.law.umaryland.edu/cgi/viewcontent.cgi?article=1663\&context=mjil (accessed 28 July 2020).

7. Hollist K.E. 2015. Time to be grown- ups about video gaming: the rising esports industry and the need for regulation. Arizona Law Review, 57: 823-847. Available at: https://arizonalawreview.org/pdf/57-3/57arizlrev823.pdf (accessed 28 July 2020).

8. Martinelli J. 2019. The Challenges of Implementing a Governing Body for Regulating ESports. University of Miami International and Comparative Law Review, 26 (2): 499-424. 
Available at: https://repository.law.miami.edu/cgi/viewcontent.cgi?article=1329\&context=umiclr (accessed 28 July 2020).

9. NewZoo. 2020. 2020 Global Esports Market Report. Available at: https://strivesponsorship.com/wp-content/uploads/2020/03/Global-Esports-Market-Report2020.pdf (accessed 28 July 2020).

10. Owens M.D. 2016. What's in a Name? eSports, Betting, and Gaming Law. Gaming law review and economics, 20 (7): 567-570.

11. Vansyngel S., Velpry A., Besombes N. 2018. French esports institutionalization. In: Proceedings of the 2nd International GamiFIN Conference (Pori, Finland, May 21-23, 2018). Pori: $123-130$.

12. Windholz E.L. 2020. Governing Esports: Public Policy, Regulation and the Law (2020). Sports Law eJournal, 1 (1): 1-37.

13. Yue Y. 2018. Research on eSports and eSports Industry in China. Available at: https://library.olympic.org/Default/doc/SYRACUSE/174917/research-on-esports-and-esportsindustry-in-china-yang-yue?_lg=en- GB (accessed 28 July 2020).

\section{ИНФОРМАЦИЯ ОБ АВТОРЕ}

Редькина Алена Игоревна, кандидат юридических наук, доцент кафедры спортивного права Московского государственного юридического университета им. О.Е. Кутафина (МГЮА), г. Москва, Россия

\section{INFORMATION ABOUT THE AUTHOR}

Alena I. Redkina, $\mathrm{PhD}$ (Law), Assistant Professor of Sports Law Department of the Kutafin Moscow State Law University, Moscow, Russia 